\title{
A PSTOL-like gene, TaPSTOL, controls a number of agronomically important traits in wheat
}

\author{
Matthew J. Milner ${ }^{1}$, Rhian M. Howells ${ }^{1}$, Melanie Craze ${ }^{1}$, Sarah Bowden ${ }^{1}$, Neil Graham² and Emma J. Wallington ${ }^{1 *}$ (D
}

\begin{abstract}
Background: Phosphorus (P) is an essential macronutrient for plant growth, and is required in large quantities by elite varieties of crops to maintain yields. Approximately $70 \%$ of global cultivated land suffers from P deficiency, and it has recently been estimated that worldwide $P$ resources will be exhausted by the end of this century, increasing the demand for crops more efficient in their $\mathrm{P}$ usage. A greater understanding of how plants are able to maintain yield with lower $P$ inputs is, therefore, highly desirable to both breeders and farmers. Here, we clone the wheat (Triticum aestivum L.) homologue of the rice PSTOL gene (OSPSTOL), and characterize its role in phosphate nutrition plus other agronomically important traits.

Results: TaPSTOL is a single copy gene located on the short arm of chromosome 5 A, encoding a putative kinase protein, and shares a high level of sequence similarity to OsPSTOL. We re-sequenced TaPSTOL from 24 different wheat accessions and (3) three T. durum varieties. No sequence differences were detected in 26 of the accessions, whereas two indels were identified in the promoter region of one of the durum wheats. We characterised the expression of TAPSTOL under different P concentrations and demonstrated that the promoter was induced in root tips and hairs under P limiting conditions. Overexpression and RNAi silencing of TaPSTOL in transgenic wheat lines showed that there was a significant effect upon root biomass, flowering time independent of $\mathrm{P}$ treatment, tiller number and seed yield, correlating with the expression of TaPSTOL. However this did not increase PUE as elevated $P$ concentration in the grain did not correspond to increased yields.

Conclusions: Manipulation of TaPSTOL expression in wheat shows it is responsible for many of the previously described phenotypic advantages as OSPSTOL except yield. Furthermore, we show TaPSTOL contributes to additional agronomically important traits including flowering time and grain size. Analysis of TAPSTOL sequences from a broad selection of wheat varieties, encompassing $91 \%$ of the genetic diversity in UK bread wheat, showed that there is very little genetic variation in this gene, which would suggest that this locus may have been under high selection pressure.
\end{abstract}

Keywords: Phosphate, PSTOL, Wheat, P, Seed size, Seed number, Flowering time, PUE

\section{Background}

Phosphorus (P) is an essential macronutrient that is required for all major developmental processes in plants and is considered to be one of the most limiting plant nutrients to global agricultural production. Approximately $70 \%$ of global cultivated land suffers from phosphate deficiency, making research into phosphate nutrition a priority for both scientists and farmers [1-3].

\footnotetext{
* Correspondence: emma.wallington@niab.com

'The John Bingham Laboratory, NIAB, Huntingdon Road, Cambridge CB3 OLE, UK

Full list of author information is available at the end of the article
}

Phosphate is usually taken up in the orthophosphate forms $\left(\mathrm{P}_{\mathrm{i}}\right)$ which are available at low concentrations in the soil solution [4]. This low availability can be compounded by the soil chemistry in which soils high in clay can bind the $\mathrm{P}_{\mathrm{i}}$ requiring large amounts of fertilizer to be applied to maintain high yields [4-6]. To compound the problem of $\mathrm{P}$ limiting growth and yield, recent estimates suggest that only $20-30 \%$ of the inorganic phosphate $\left(P_{i}\right)$ added to fields by farmers is assimilated by plants [7]. An increased understanding of how plants use $P_{i}$ and the current inefficiency of $P_{i}$ assimilation would be of economic benefit to farmers and also

(c) The Author(s). 2018 Open Access This article is distributed under the terms of the Creative Commons Attribution 4.0 International License (http://creativecommons.org/licenses/by/4.0/), which permits unrestricted use, distribution, and 
potentially alleviate environmental problems resulting from large scale agricultural production. Wheat (Triticum aestivum L.) is one of the most important crops worldwide and grown on more than 240 million hectares in 2016 [8]. $\mathrm{P}$ is one of the three most important nutrients for growth and yield improvement in wheat $[9,10]$. Therefore an improvement in phosphate use efficiency (PUE) in wheat could potentially have a large global impact over 200 million hectares.

Recent advances in our understanding of the molecular mechanisms by which different plant species adapt to low-phosphate stress, the regulation and expression of phosphorus metabolism genes and alleles to deal with phosphate limitation, have enabled the design of more effective breeding strategies to produce highly phosphate efficient crops [11, 12]. A number of the underlying genes involved in the response of plants to low $\mathrm{P}$ are highly conserved and play similar roles in a number of diverse plant species including both model system and crop species. Thus, a greater understanding of the pathways involved in phosphate acquisition and signalling will allow breeders and plant molecular biologists to develop more efficient crops. Identification of these conserved pathways and genes from model organisms, and the subsequent transfer of this knowledge to crop species, would therefore allow farmers to optimize fertilizer use, resulting in increased food production efficiency with lower environmental cost.

One such locus which is believed to be important is the recent identification of the PUP1 locus from rice which contains a putative kinase gene called Phosphate Starvation Tolerance 1 (PSTOL) [13-16]. The PUP1 locus was originally identified in an upland variety of rice, Kasalath, yet is absent from most rice cultivars [17-19]. Rice varieties which have this genomic introgression containing the PSTOL gene, show increased biomass, increased root growth, increased tiller number and yield increases of up to $30 \%$ when grown under low $\mathrm{P}$ conditions whereas no deleterious consequences were seen when grown under normal soil fertility conditions $[19,20]$. The identification of OsPSTOL and its role in helping rice tolerate low $\mathrm{P}$ conditions has led to the belief that we can engineer PUE into many crop species using translational science from gains in other model species.

Others have identified homologous PSTOL-like genes in both maize and sorghum, based upon QTL analysis and sequence homology. Further evidence of the role of PSTOL-like genes in PUE has been supported through QTL mapping rather than direct molecular characterization of candidate genes [21, 22]. Criteria to identify other potential PSTOL like genes has included identification of protein domains such as ATP kinase domains and on DNA sequence conservation meeting certain bioinformatic cut-offs for genes underlying these QTL. However some of these homologues appear to have differences in their gene structure such as number and length of introns and UTRs. Despite the lack of a highly conserved gene in most plant species, it is critical to understand whether other PSTOL genes exist in other important crop species and if they can be exploited.

Our study identifies a putative wheat PSTOL gene (TaPSTOL) and characterizes its role in PUE and other phenotypes of agronomic importance.

\section{Methods \\ Gene identification}

The OsPSTOL coding sequence from EMBL (AB458444.1) was used as a query for BLAST searches of the wheat genome (IWGSC 2014) and expressed sequence tag (EST) databases in ensembl, GenBank, Komugi and URGI [23-27]. Gene prediction was carried out using FGENESH [28]. Protein domain prediction was found using IntroProScan [29].

\section{Nullisomic (N) / Tetrasomic (T) wheat lines}

PCR conditions for the verification of TaPSTOL homeologues were first optimized with wheat cv. Fielder DNA using a gradient from 53 to $63{ }^{\circ} \mathrm{C} \mathrm{T}_{\mathrm{m}}$ with and without 2\% DMSO (final concentration) using FastStart ${ }^{\text {tw }}$ Taq DNA Polymerase (SIGMA). All primers used in this study are listed in Additional file 1: Table S1. All three primer pairs amplified the predicted product under all conditions tested (Additional file 2: Figure S1). To reduce the stringency, the annealing temperature was then reduced to $55{ }^{\circ} \mathrm{C}$ to allow for small sequence variations and amplification of other distant homeologues using the nullisomic / tetrasomic wheat DNA [30].

\section{Creation of plasmid constructs}

TaPSTOL was PCR amplified from genomic DNA extracted from wheat cultivar Chinese Spring using primers TaPUP-K46-F and TaPUP-K46-R with Phusion Hotstart II DNA Polymerase (Thermofisher). Amplicons were cloned into PJET2.1 (Thermofisher) and fully sequenced. The full length gene was then reamplified from pJET-TaPSTOL with TaPUP-K46-F-PvuII and TaPUP-K46-R-XbaI to add $P v u I I$ and $X b a I$ restriction sites plus a monocot ribosome binding site, CCACC [31], and cloned into pENTR-1A digested with $\mathrm{Dra \textrm {I }}$ and $\mathrm{Xba \textrm {I }}$ (Thermofisher). TaPSTOL was then recombined into the binary vector $\mathrm{pSc} 4 \mathrm{Act}$ R1R2 [32] using a Gateway LR Clonase II Kit (Thermofisher) to create pRMH007. TaPSTOL was expressed in planta from the rice Actin promoter [33] and transcripts terminated by the A. tumefaciens nopaline synthase terminator (tNOS). The first $350 \mathrm{bp}$ of the TaPSTOL sequence selected to trigger silencing by RNAi, was amplified from the genomic sequence using the primers RNAi-F GW and RNAi-R GW, and recombined directly into pDONR221 
using a Gateway BP Clonase II kit (Invtrogen). The pDONR TaPSTOL insert was subsequently recombined into the binary vector pACT-IR2 in a Gateway LR reaction to create pMM2, with the TaPSTOL RNAi hairpin cassette expressed from the rice Actin promoter in planta.

The $2.4 \mathrm{~kb}$ promoter region upstream of the TaPSTOL start codon was amplified from genomic DNA extracted from Chinese Spring using primers TaPUP-prom-F and TaPUP-prom-R with Phusion Hotstart II Polymerase (Thermofisher). The resultant amplicon was ligated into pCR-Blunt (Thermofisher) and sequenced. The promoter region was then reamplified with primers TaPUP-prom-13R and TaPUP-prom-SalI. The amplicon was digested with SalI and ligated into pRMH013 digested with BmgBI and SalI. This intermediate vector containing the TaPSTOL promoter driving GUS and flanked by attL sites, was then recombined into pRLF12-R1R2-SCV to produce vector pRMH107. Additional file 3: Figure S2, shows the T-DNA regions from these constructs, which were transformed into wheat in this study.

Completed constructs were verified by restriction digest and sequencing before being electro-transformed into Agrobacterium tumefaciens. Plasmids were re-isolated from Agrobacterium cultures and verified by restriction digest prior to use in wheat experiments [34].

\section{Wheat transformation}

Wheat cv. Fielder plants were grown in controlled environment chambers (Conviron) at $20{ }^{\circ} \mathrm{C}$ day/ $15{ }^{\circ} \mathrm{C}$ night with a $16 \mathrm{~h}$ day photoperiod (approximately $400 \mu \mathrm{E} \mathrm{m}^{-2} \mathrm{~s}^{-1}$ ). Immature seeds were harvested for transformation experiments at 14-20 days post-anthesis (dpa). Isolated immature wheat embryos were co-cultivated with Agrobacterium tumefaciens for 2 days in the dark [35]. Subsequent removal of the embryonic axis and tissue culture was performed as previously described [36]. Individual plantlets were hardened off following transfer to Jiffy-7 pellets (LBS Horticulture), potted up into $9 \mathrm{~cm}$ plant pots containing M2 compost plus $5 \mathrm{~g} / \mathrm{l}$ slow release fertilizer (Osmocote Exact 15:9:9) and grown on to maturity and seed harvest in controlled environment chambers, as above.

\section{DNA analysis of transformed wheat plants}

Plantlets which regenerated under G418 selection in tissue culture were transferred to Jiffy-7 pellets and validated using an nptII copy number assay relative to a single copy wheat gene amplicon, GaMyb, normalised to a known single copy wheat line. Primers and Taqman probes were used at a concentration of $10 \mu \mathrm{M}$ in a $10 \mu \mathrm{l}$ multiplex reaction using ABsolute Blue qPCR ROX mix (Thermofisher) with the standard run conditions for the ABI $7900 \mathrm{HT}$. The relative quantification, $\Delta \Delta \mathrm{Ct}$, values were calculated to determine nptII copy number in the
$\mathrm{T}_{0}$ and subsequent generations [37]. Homozygous and null transgenic lines were identified on the basis of nptII copy number and segregation analysis. WT Fielder plants were null segregates.

\section{Plant growth conditions}

WT and transgenic lines were grown under low P conditions in sand and fertilized with nutrient solution [38] or under fertilized M2 compost conditions, as above. Total dry shoot weight, seed weight (yield per plant), seed number, seed size, tiller number and $P$ concentration via ICP-MS were measured. Biological replicates each contained 14 plants per line and were grown until seed maturation. Tissues were allowed to dry for a further two weeks before harvesting. For low $\mathrm{P}$ conditions plants were germinated in sand and watered with $25 \mathrm{~mL}$ of a Magnavaca solution containing $3 \mu \mathrm{M} \mathrm{KH_{2 }} \mathrm{PO}_{4}, 1.3 \mathrm{mM}$ $\mathrm{NH}_{4} \mathrm{NO}_{3}, 3.52 \mathrm{mM} \mathrm{Ca}\left(\mathrm{NO}_{3}\right)_{2}, 0.58 \mathrm{mM}, \mathrm{KCl}, 0.58 \mathrm{mM}$ $\mathrm{K}_{2} \mathrm{SO}_{4}, 0.56 \mathrm{mM} \mathrm{KNO}, 0.86 \mathrm{mM} \mathrm{Mg}\left(\mathrm{NO}_{3}\right)_{2} 0.13 \mathrm{mM}$ $\mathrm{H}_{3} \mathrm{BO}_{3}, 5 \mu \mathrm{M} \mathrm{MnCl} \mathrm{M}_{2}, 0.4 \mu \mathrm{M} \mathrm{Na}_{2} \mathrm{MoO}_{4}, 10 \mu \mathrm{M} \mathrm{ZnSO}$, $0.3 \mu \mathrm{M} \mathrm{CuSO}_{4}, \mathrm{Fe}\left(\mathrm{NO}_{3}\right)_{3}$ and $2 \mathrm{mM}$ MES (pH 5.5) twice a week until maturity. Plants were grown in a controlled growth chamber under $16 \mathrm{~h}$ light and $20{ }^{\circ} \mathrm{C} / 15{ }^{\circ} \mathrm{C}$ day night temperatures.

\section{RNA expression analysis}

Fielder seedlings were grown for seven days in $2.2 \mathrm{~L}$ pots containing Magnavaca solution as listed above and sup-

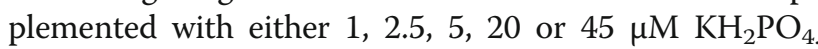
Plants were grown for 7 days before harvesting tissue and separating the samples into root and shoot tissues for analysis. Total RNA was isolated from both roots and shoots for each P treatment using an RNeasy Kit (Qiagen) and treated with DNaseI (Thermofisher) prior to cDNA synthesis from $500 \mathrm{ng}$ of total RNA using Omniscript RT Kit (Qiagen). The cDNA was diluted 1:2 with water and $0.5 \mu \mathrm{L}$ was used as template in each RT-PCR reaction. Expression levels were quantified by quantitative PCR in triplicate reactions from three biological replications using SYBR Green JumpStartTaq ReadyMix (SIGMA) with the standard run conditions for the ABI 7900 HT. TaPSTOL expression was compared to two reference genes TaUbiquitin and TaEF1 $\alpha$. Primers used for amplification of transcripts were TaPSTOL-Q-F and TaPSTOL-Q-R, Ubi-F and Ubi-R for Ubiquitin [39] or EF1 $\alpha-\mathrm{F}$ and $\mathrm{EF} 1 \alpha-\mathrm{R}$ for $E F 1 \alpha$ [40]. Data shown is in comparison to Ubiquitin for ease as both reference genes showed similar differences in expression.

\section{Genomic comparison}

Primers were designed to amplify a $3.3 \mathrm{~kb}$ fragment of TaPSTOL which included the $5^{\prime}$ upstream region and ORF from DNA extracted from Chinese Spring using 
the primers TaPUP-prom-F and TaPUP-prom-R. Genomic DNA was amplified from bread wheat varieties Alchemy, Banco, Bersee, Bridgadier Brompton, Claire, Copain, Cordiale, Fielder, Flamingo, Gladiator, Hereward, Holdfast, Kloka, Maris Fundin, Paragon, Rialto, Robigus, Slejpner, Soissons, Spark, Steadfast, Stetson, Xi19 and Chinese Spring, plus three wild T. turgidum ssp. dicoccoides accessions (PI 503314, PI 414722, and PI 428097) sourced from the USDA-ARS National Small Grains Collection. Genomic DNA was extracted using the Tanksley method [41].

\section{Gus staining of wheat tissues}

Whole 10-day seedlings grown on sand watered once with hydroponic solution containing $3 \mu \mathrm{M}$ P, were stained in X-Gluc solution (0.1 $\mathrm{M} \mathrm{NaPO}_{4}, 10 \mathrm{mM}$ EDTA $\mathrm{pH}$ 7.0, $0.5 \mathrm{mM} \mathrm{K}$ Ferricyanide, $0.5 \mathrm{mM} \mathrm{K}$ Ferrocyanide, $1.0 \mathrm{mM}$ X-Glucuronide, $0.1 \%$ Triton X100, pH 7.0) overnight at $37^{\circ} \mathrm{C}$, then destained in $70 \%$ ethanol [42].

\section{Digestion and elemental analysis of plant material}

Dried samples of leaf, root and grain $(\sim 0.2 \mathrm{~g})$ were digested and analysed for elemental content as described by Thomas et al. [43].

\section{Phosphate use efficiency calculations}

Definitions of PPUE and PER were taken from [44]. PPUE was calculated as yield/ $\mathrm{P}$ concentration for an individual treatment. PER was calculated as yield / (P concentration * yield) for an individual treatment. ANOVAs were run using $R$ and the aov and Tukey functions with the null hypothesis of no difference between lines. Tukey's post hoc test was added to identify each significant interaction between the lines tested.

\section{Results}

\section{Identification of TaPSTOL}

Our TaPSTOL candidate was identified following BLAST searches [45] using the OsPSTOL coding sequence to the first wheat genome release (IWGSC 2014 and EST collections; this has subsequently been annotated as gene model Traes_5AS_AA3DC6A5F on ENSEMBL (IWGSC, 2014 release, Ensembl). The identified homologue is located on the short arm of chromosome 5A and shares $90 \%$ homology at the DNA level with the rice gene sequence. Further analysis showed that the rice and wheat predicted proteins share $74.2 \%$ identity and $92.7 \%$ similarity at the amino acid level (Additional file 4: Figure S3). OsPSTOL and TaPSTOL both possess single exons, and their predicted proteins are similar in size: 324 amino acids and 289 amino acids, respectively. InterProScan identified two protein domains which are predicted in both the wheat and rice PSTOL genes which include a protein kinase ATP-binding region signature (PS00107) located from amino acids 9-31 and a Serine/Threonine protein kinase active-site signature (PS00108) located from amino acids 126-138. The second best BLASTp hit to OsPSTOL in the wheat genome is encoded by a gene located on chromosome 3B, which shared only 54\% amino acid identity suggesting that three sub-genome specific homologues were not present in wheat. A putative phosphate starvation activation domain thought to be bound by PHR1, also known as a P1BS binding site, was identified at -1156 to $-1149 \mathrm{bp}$ in the predicted promoter region of TaPSTOL [30]. To provide additional evidence that there is only a single gene present in wheat, the TaPSTOL sequence was also used to conduct a BLASTn search against Triticum urartu (A genome), Aegilops speltoides (B genome) and Aegilops tauschii (D genome) sequence databases. A single near perfect match was found for T.urartu. However no strong match was found in either the A.speltoides or the $A$. tauschii genome sequences. The best match for A. speltoides was 929 bp but with only $73 \%$ identity and for A. tauschii the best match was 266 bp with $85 \%$ identity [24, 27].

Due to the incomplete nature of the wheat genome assembly, we confirmed the absence of TaPSTOL homoeologues on chromosomes $5 \mathrm{~B}$ and $5 \mathrm{D}$ by screening the Chinese Spring nulli-tetrasomic deletion lines [46]. PCRs using three primer combinations were designed using the 5A TaPSTOL promoter and coding region. This revealed only one copy of the PSTOL gene on chromosome $5 \mathrm{~A}$ and no homoeologues on $5 \mathrm{~B}$ or $5 \mathrm{D}$ (Additional file 2: Figure S1). To allow for potential small sequence variations in primer hybridisation sites, the stringency of primer annealing was reduced to $55{ }^{\circ} \mathrm{C}$, but no additional amplicons were amplified. This suggests that only a single copy of TaPSTOL exists in Chinese Spring and that it is located on the short arm of chromosome 5A.

To search for sequence variation which might exist in the TaPSTOL gene or regulatory regions, we re-sequenced TaPSTOL from different wheat accessions: (1) the 22 founders of two bread wheat multiparent advanced generation inter-cross (MAGIC) populations (NIAB Elite MAGIC, [47]; NIAB Diverse MAGIC, [48]) that collectively capture $91 \%$ of genetic diversity in UK wheat; (2) spring varieties Fielder (USA) and Chinese Spring (China); and (3) three $T$. durum accessions (Additional file 5: Table S2). No sequence differences in any of the bread wheat lines tested were detected. A small variant was found in $T$. durum accession PI503314 which contained two indels in the promoter region. The first was a $13 \mathrm{bp}$ insertion at 355 and the second was a 34 bp deletion at $-704 \mathrm{bp}$. The A-genome sequence from other two dicoccoides accessions was identical to the hexaploid wheat sequence. No differences were found in the coding region in any of the lines tested. 


\section{TaPSTOL gene expression}

To further understand if Traes_5AS_AA3DC6A5F is the putative wheat $P S T O L$ homologue, Fielder wheat plants were grown with varying levels of $\mathrm{P}(1,5,10,20$ and $45 \mu \mathrm{M}$ P) in hydroponics for seven days and expression of TaPSTOL was measured in both roots and shoots (Fig. 1). TaPSTOL is expressed relatively evenly in both root and shoot tissues, however TaPSTOL transcript abundance decreases with increasing $\mathrm{P}$ concentration in both tissue types. To further examine the expression of TaPSTOL, a $2.4 \mathrm{~kb}$ region directly upstream of the start codon was cloned and used to drive the expression of a GUS reporter gene. Characterization of 10 transformed wheat lines showed very low to no expression in roots, shoots or flowers of plants when grown under standard conditions in compost. When plants were grown under nutrient limiting conditions, TaPSTOL expression was found in the roots and shoots, with the highest expression in the root tips of both primary and lateral roots and coleoptiles (Fig. 2). Expression could also be seen in both the leaf trichomes and root hairs. Similar patterns of expression where observed in all ten lines tested.

\section{Characterization of TaPSTOL overexpression and RNAi knockdown lines in wheat}

In order to evaluate the function of TaPSTOL, and compare to that of known OsPSTOL phenotypes, both over expression (OE) and RNA interference (RNAi) wheat transgenic lines were created. The expression level of TaPSTOL in thirty three OE and forty RNAi independent $\mathrm{T}_{0}$ lines was measured. Lines were selected for further study with a high over-expression $(30 \times$ higher than wild type), low level overexpression (3X higher than wild type), a highly knocked down line ( $90 \%$ knock down)
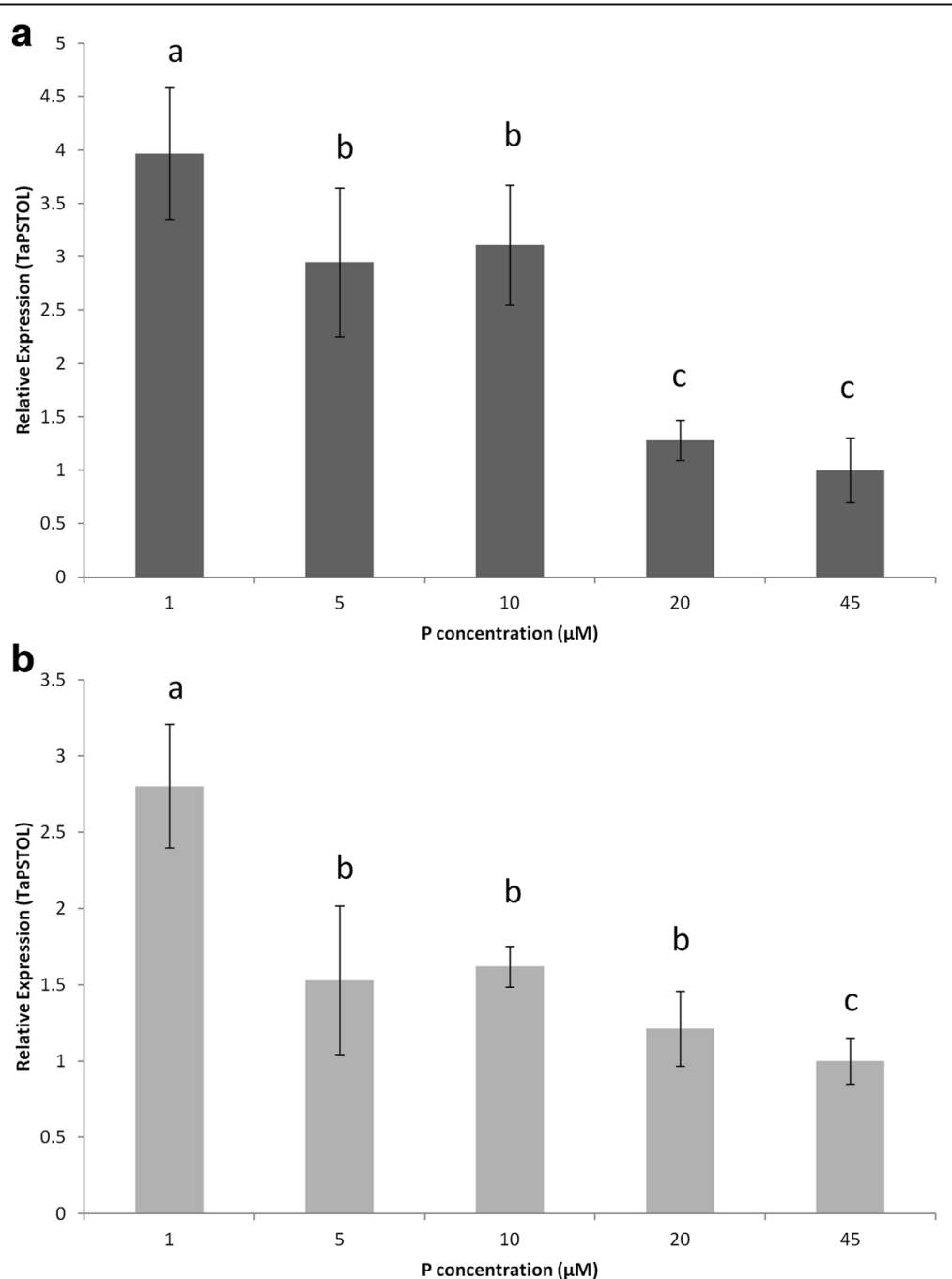

Fig. 1 Expression of TaPSTOL mRNA in wheat grown under a range of P concentrations. Expression of TaPSTOL in (a) roots and (b) shoots is shown relative to TaUbiquitin mRNA after seven days growth in hydroponic solution. Error bars are SE of three biological replications. Letters represent a significant difference ( $p$ val $<0.05$ ) between the same tissue type at any $\mathrm{P}$ concentration 


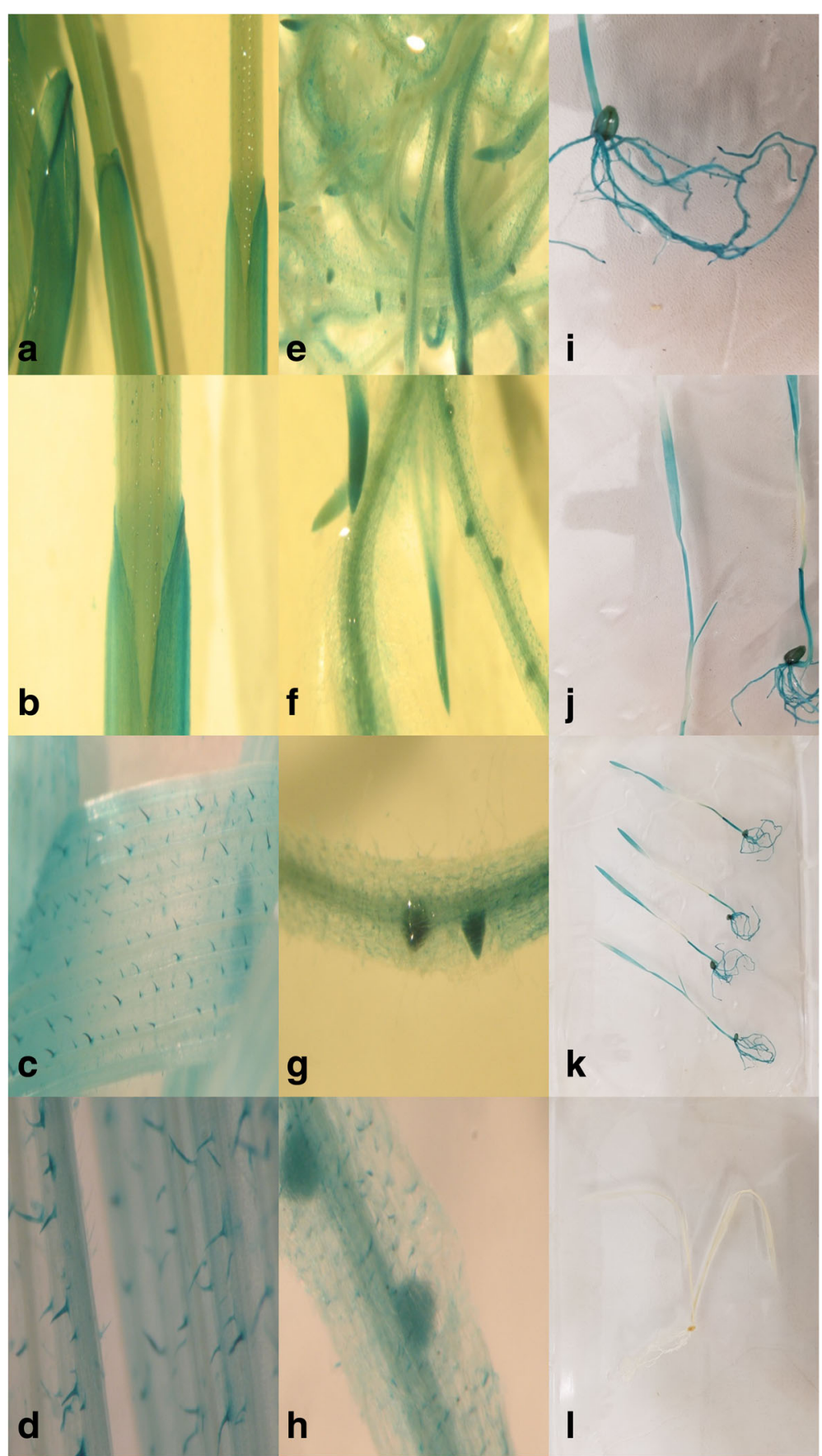

Fig. 2 Characterisation of TAPSTOL promoter-GUS transcriptional fusions in wheat. Seedlings were grown in sand watered with $-P$ hydroponic solution for 10 days after germination. Low magnification of a multiple coleoptiles, $\mathbf{b}$ a single coleoptile, $\mathbf{c}$ leaf trichomes. $\mathbf{d}$ Higher magnification of trichomes. Low magnification of (e) multiple roots, (f) isolated roots. Higher magnification of lateral root initials $(\mathbf{g}, \mathbf{h})$. Low magnification of root system (i), shoots (j), four plants showing TaPSTOL:GUS expression (k), non-transformed control plant (I) grown under same conditions

and a lower level of knock down (80\% knock down), line here to referred as OE-1, OE-2, RNAi-1 and RNAi-2 respectively. Homozygous $\mathrm{T}_{2}$ plants were selected on the basis of $n p t I I$ qPCR copy number analysis and resulting lines were phenotypically assessed under both low $\mathrm{P}$ conditions $(3 \mu \mathrm{M} \mathrm{P})$ in sand to better control P levels and standard P growth conditions, (M2 compost with $109 \mathrm{mg} / \mathrm{l}$ available $\mathrm{P}$ ).

For OE and RNAi lines grown on sand (fed twice a week with Magnavaca solution containing low $\mathrm{P}$ at $3 \mu \mathrm{M})$ a significant difference in the dry weight of roots from both the highest modified expression levels of $\mathrm{OE}$ 
and RNAi plants could be seen when grown to seed (ie OE-1 and RNAi-1, Fig. 3a). No significant differences in dry weight were found for the shoots of the OE or RNAi transgenic plants (Fig. $3 \mathrm{~b}$ and e).

No difference in tiller number under low $\mathrm{P}$ conditions was seen in either the OE or RNAi lines (Fig. 3c). However, when grown on M2 compost, a significant difference in the tiller number was observed, with RNAi and $\mathrm{OE}$ lines showing a significantly lower and significantly higher tiller number, respectively $(\mathrm{p}$ val $<0.05$ ) (Fig. 3f). Despite the difference in tiller number, modification of TaPSTOL expression showed no significant effect on total yield between the lines tested with growth in compost.
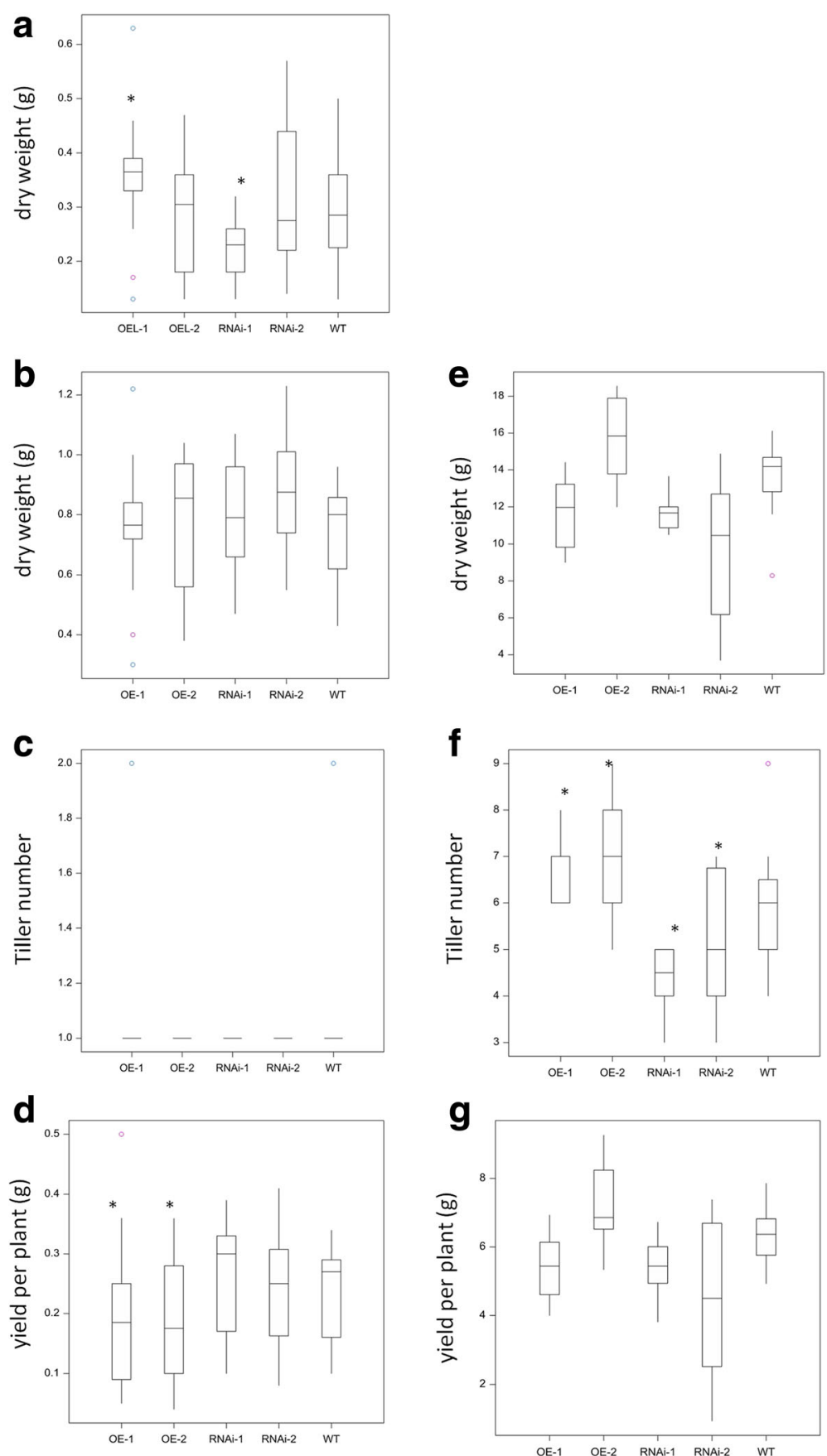

Fig. 3 Agronomic measurements of OE and RNAi lines. Plants were grown under both low P ( $3 \mu \mathrm{M})$ conditions in sand to seed (a-d) or grown in M2 compost to seed $(\mathbf{e}-\mathbf{g})$. Dry weight of transgenic wheat $\mathbf{a}$ roots, or $\mathbf{b}$ shoots; $\mathbf{c}$ average tiller number; $\mathbf{d}$ yield per plant; e dry weight of shoots; faverage tiller number; $\mathbf{g}$ yield per plant. Asterisk indicates significant difference $p$ val $<0.05$ to WT Fielder 
During these experiments a novel phenotype was observed under low $\mathrm{P}$ conditions, namely a difference in the time to flowering, defined by time until growth stage 49 in days [49]. The RNAi lines were significantly earlier in flowering relative to the WT plants by almost two days $(p \mathrm{val}<0.05)$ (Fig. 4a). As anticipated, the converse phenotype was seen for the $\mathrm{OE}$ lines as the time taken to flowering was significantly longer than the WT plants (p val. < 0.05). This difference in flowering time correlated with a significant negative effect on the total yield under low $\mathrm{P}$ conditions $(3 \mu \mathrm{M})$ but not under $\mathrm{M} 2$ grown conditions for lines overexpressing TaPSTOL (Fig. 3d and g). The effect on flowering time was less pronounced under M2 compost growth conditions as only the highest overexpression line (OE-1) and highest knockdown line (RNAi-1) showed significant variation relative to WT Fielder (Fig. 4b).

A change in the overall root biomass production with a significant difference in root DW under low $\mathrm{P}$ for the both the highest (OE-1) and lowest (RNAi-1) TaPSTOL transgenic lines was observed (Fig. 3). While the overall total DW (root DW + shoot DW) under low P conditions was unaffected, there was an observable shift in DW from the root to shoot.

TaPSTOL transgenic lines also showed differences in seed size. $\mathrm{OE}$ lines grown under $\mathrm{P}$ stress produced a
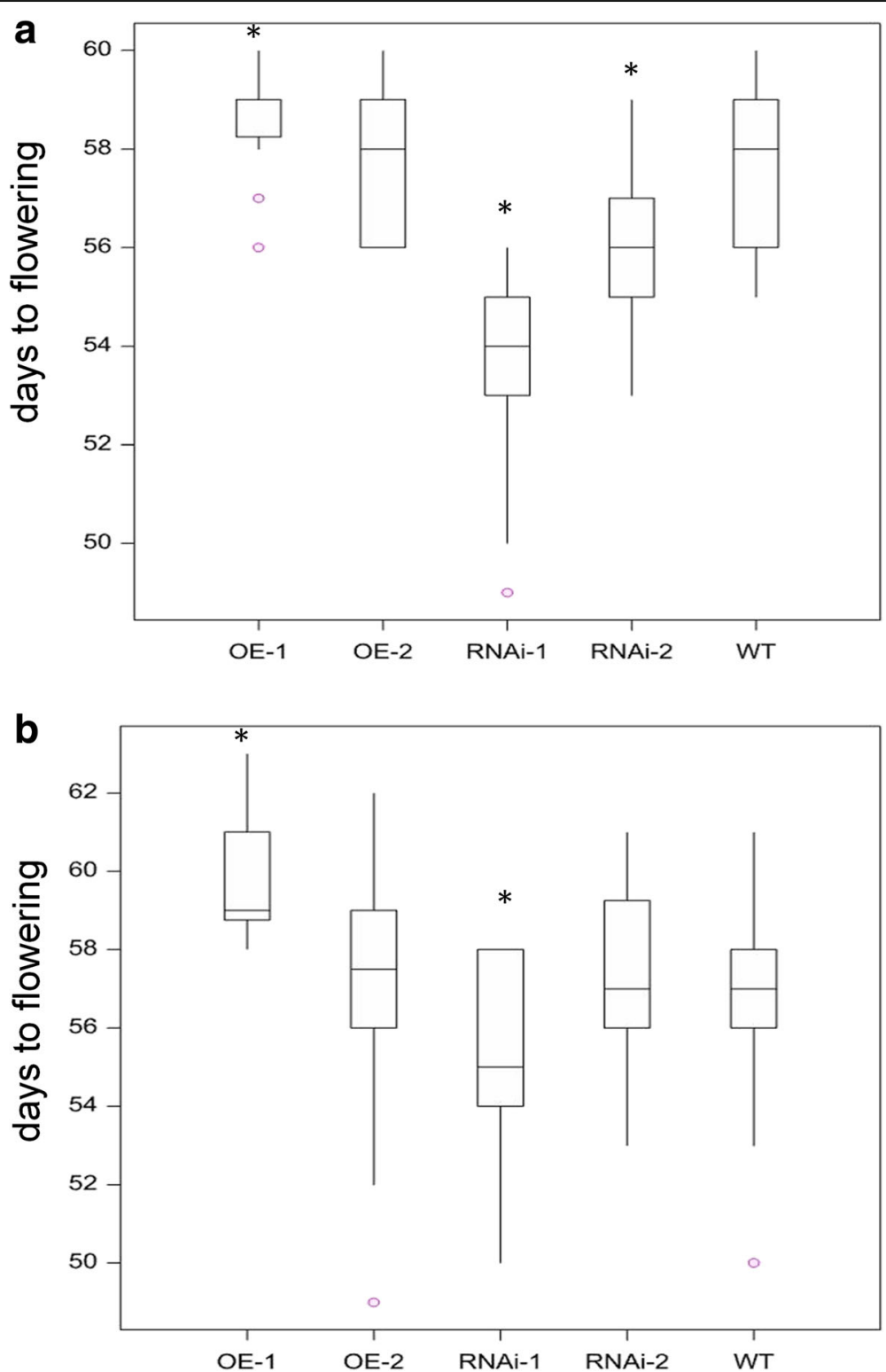

Fig. 4 Flowering time measurements of OE and RNAi lines. Days to flowering, defined as Zadok stage 49, is shown under either a low phosphate conditions in sand ( $3 \mu \mathrm{M}$ P) or $\mathbf{b} \mathrm{M} 2$ compost conditions. Asterisk indicates significant difference $p$ val $<0.05$ to WT Fielder 
decreased number of seeds compared to both RNAi and WT plants. In contrast, while OE lines produced far fewer seeds, each seed was $40-50 \%$ larger than the RNAi seeds and 30-40\% larger than the WT seeds (Fig. 5b and d). This effect was mainly observed by an increase in the width of the seeds (Fig. 6) while the length remained similar.

Total P concentration in the roots, shoot and seeds was also measured in five plants chosen randomly for each transgenic line grown under low $\mathrm{P}$ conditions and for shoots and seeds grown under compost conditions. No significant differences in P concentration were seen between root or shoot tissues grown under either condition in any of the sampled lines (Fig. 7a and b). There was a significant difference in the amount of $\mathrm{P}$ in the seeds of the RNAi-1 and OE-1 and OE-2 relative to WT (Fig. 7c). The differences in $\mathrm{P}$ concentration showed a lower $\mathrm{P}$ concentration in the RNAi line and higher $\mathrm{P}_{\mathrm{i}}$ concentration in the $\mathrm{OE}$ lines $(\mathrm{p}$ val $<0.05)$. Other essential elements including $\mathrm{K}, \mathrm{Ca}, \mathrm{Mg}, \mathrm{Mn}, \mathrm{Zn}$, $\mathrm{Cu}, \mathrm{Fe}, \mathrm{Mo}, \mathrm{S}$, and $\mathrm{Co}$ were also tested for significant differences between lines and no significant differences were found.

\section{The role of TaPSTOL in phosphorus use efficiency:}

To understand how modification of TaPSTOL expression changes the PUE of wheat. The Physiological P use efficiency (PPUE) and the P efficiency ratio (PER) were measured (Fig. 8). There was a significant difference in the PPUE and PER when plants were grown on limiting $\mathrm{P}(p$ val $<0.001)$. The OE lines showed a significantly lower PPUE and PER, probably due to a significant increase in $\mathrm{P}$ in the grain accompanied by a decrease in yield. These differences in PPUE and PER were not observed under compost growth conditions, as no difference in the $\mathrm{P}$ concentration in the grain or differences in yield were seen.

\section{Discussion}

The need to drive efficiency in global agricultural production has led to the elucidation of a number of key genes in breeding for phosphate efficient crops. Here we
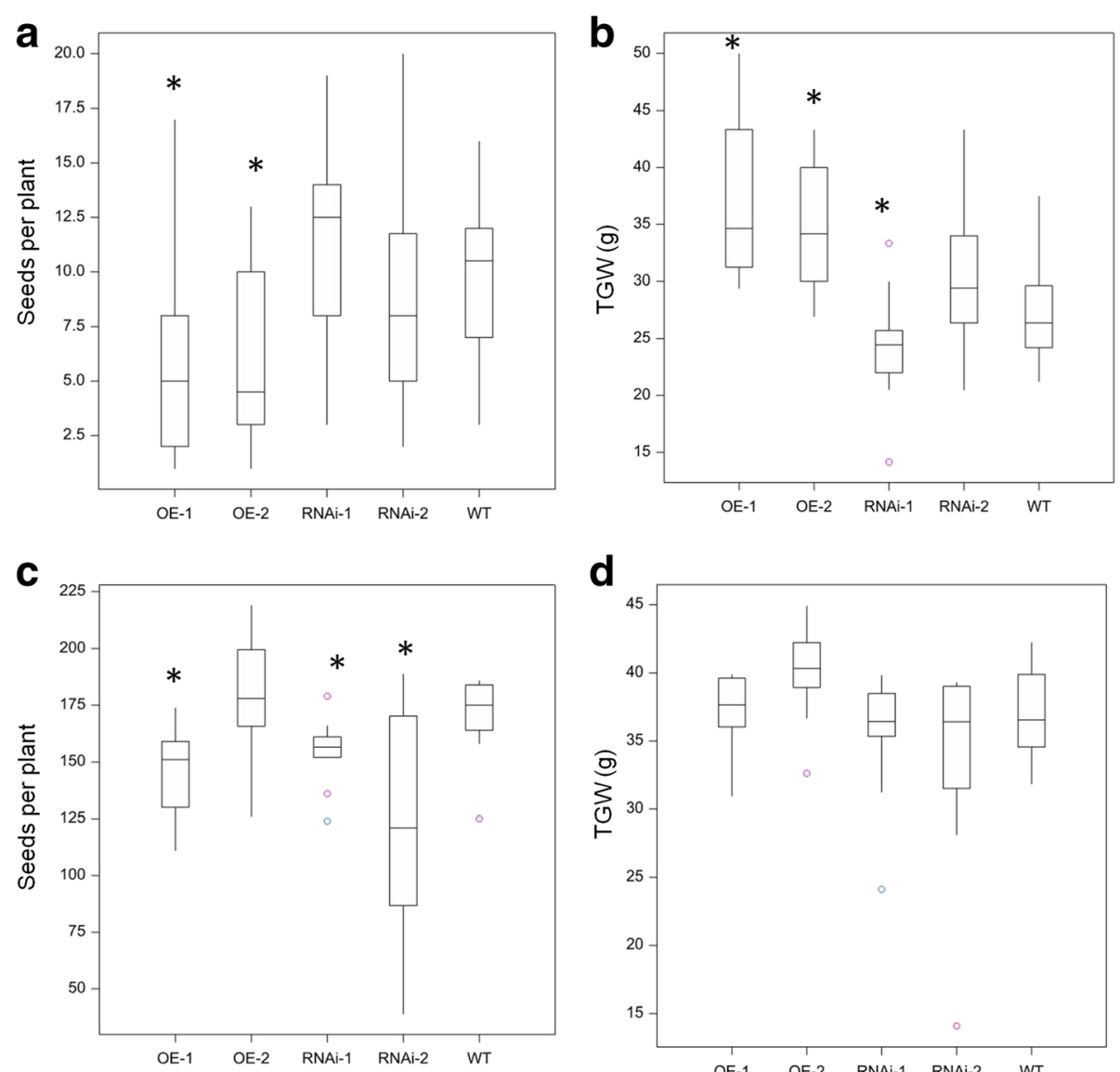

Fig. 5 Seed yield parameters of OE and RNAi lines. Number of seeds per plant and thousand grain weight for TaPSTOL modified transgenic wheat plants when grown in $\mathbf{a}$ and $\mathbf{b}$ sand with low $\mathrm{P}$ conditions $(3 \mu \mathrm{M})$; or $\mathbf{c}$ and $\mathbf{d}$ in $\mathrm{M} 2$ compost. Asterisk indicates significant difference, $p$ val $<0.05$ relative to WT Fielder 


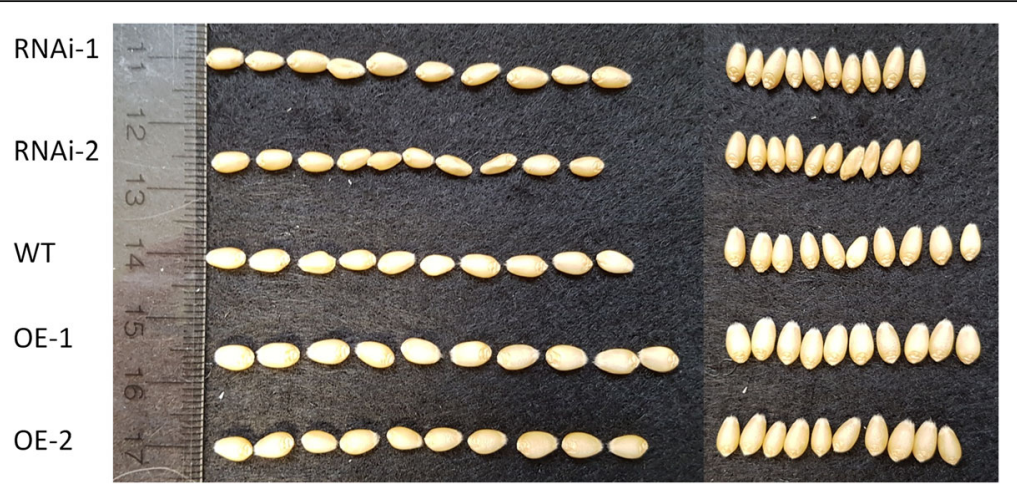

Fig. 6 Comparison of seed size from TaPSTOL RNAi or OE plants. Ten seeds of TaPSTOL RNAi or OE lines plus WT Fielder grown on low P (3 $\mu$ M P) on sand

set out to identify and characterize the wheat homologue of OsPSTOL, which we denote as TaPSTOL, and compare the effect of manipulating its expression on a number of agronomic traits both under compost and low $\mathrm{P}$ conditions. The rice gene OsPSTOL has been shown to confer phenotypes beneficial to growth on $\mathrm{P}$ limiting soils, including increased grain yield, root and shoot biomass and increased tillering $[14,15,18,47]$. Our data indicates that many of these PSTOL associated phenotypes are conserved between rice and wheat, including altered root growth under low P conditions (Fig. 3a), increased P content in the grain (Fig. 7c), and increased tiller number (Fig. 3f). There are, however, subtle differences as to when these phenotypes are exhibited in wheat as compared to rice; for instance, the increased tillering phenotype in wheat was only observed in plants grown in compost, whereas in rice, it was also found under P limiting conditions [14]. These differences in the conditions under which the increase in tillering occurs, might be a result of the stringent $\mathrm{P}$ limiting conditions in which the plants were grown in sand or the compost system used here to represent a replete $\mathrm{P}$ substrate. They could also be due to inherent differences between the two crop species, or the genetic background in which the PSTOL gene was studied in both rice and wheat. These differences are worthy of further study to identify the underlying mechanism of the PSTOL gene in both species and how TaPSTOL contributes to the regulation of tillering.

While many of the observed rice OSPSTOL mediated phenotypes were mirrored in wheat, further supporting the conserved nature of the PSTOL gene, changes in biomass and yield were not observed. This might be due the choice of germplasm used to test the effect of P efficiency in wheat or the P levels chosen might be too limiting or too generous to see the effects described in rice. There is currently no published data on $\mathrm{P}$ efficiency in the variety Fielder, but other work has suggested that natural variation in $\mathrm{P}$ efficiency does exist in wheat and this may alter the effect of TaPSTOL on P efficiency [10] within a specific variety. Recent findings in rice suggest that plants which contain the PSTOL gene are not the most efficient under low $\mathrm{P}$ conditions, which suggests that other genetic loci may play a greater role in increasing $P$ efficiency [19]. Further work in both rice and wheat is required to further understand the processes by which $P$ efficiency is increased, and the role played by PSTOL in these differences. While we found PSTOL mediated phenotypic effects in common between rice and wheat, our findings also highlight that the need for more understanding of how PSTOL genes, and their interactions with other genetic loci, may make crops more efficient under P limiting conditions.

We also identified two phenotypes associated with the TaPSTOL locus which were not observed in rice, showing that TaPSTOL modulates wheat flowering time and seed size. The timing of flowering is of great agronomic importance, as it entrains fertilization and seed set with favourable environmental conditions, thus helping farmers reach full yield potential in target agricultural environments [50]. Seed size is also an important component to driving yield gains, and we can now add another locus to those previously described as factors influencing grain size in wheat $[51,52]$. It is interesting that the lack of genetic diversity at TaPSTOL in most of the wheat lines tested suggests that this gene may not have been found by traditional QTL mapping in most UK varieties, as no variation exists to be exploited in a mapping population. The lack of variation seen in the wheat cultivars tested, point to this region as having been under strong selection pressure. The majority of these bread wheat varieties originated from the UK, however additional varieties from Europe, USA and China were also included, yet did not show any variation at this locus. Only when the search is extended to the distantly related dicoccoides accessions, which originated from Israel, is some limited variation observed within TaPSTOL, limited to the promoter region. This finding is in contrast to OSPSTOL in rice where natural variation is found across species from a 

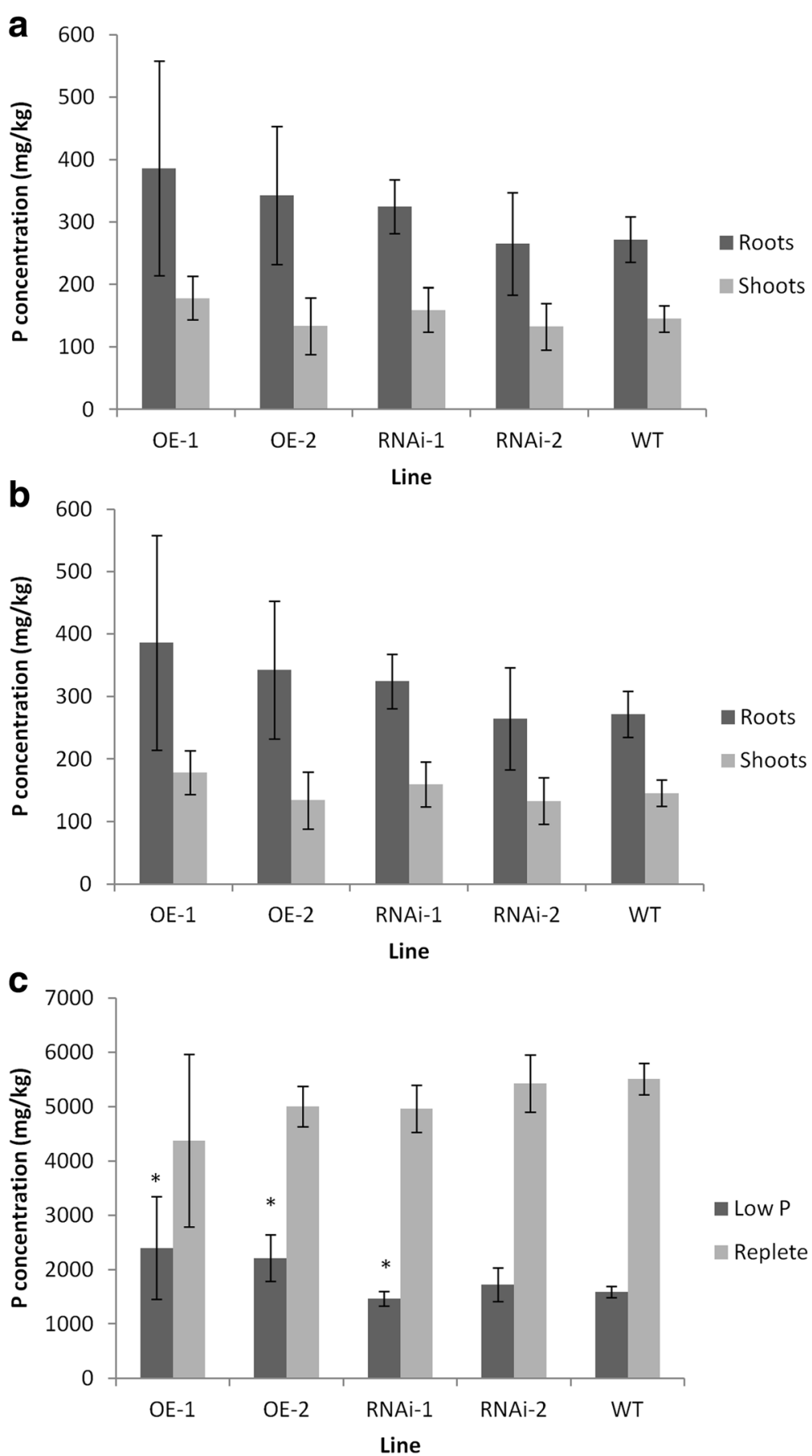

Fig. 7 P concentration in roots, shoots and grains from TaPSTOL OE and RNAi plants. a Roots or shoots grown on low P in sand ( $3 \mu \mathrm{M})$; $\mathbf{b}$ Roots or shoots grown on M2 compost. c Grains harvested from TaPSTOL transgenic wheat plants grown on either low P or compost. Asterisk indicates significant difference, $p$ val $<0.05$ relative to WT Fielder

number of different continents in both the promoter and coding regions $[17,19]$. The lack of DNA sequence variation might also be a consequence of a single PSTOL homoeologue present in the hexaploid wheat genome, located on chromosome 5A. Estimates for the number of genes present as just a single homoeologue in the hexaploid wheat genome are estimated to be in the range 3 to $11 \%[53,54]$.

Finally alteration of the expression of TaPSTOL led to changes in PUE as a decrease in yield and increase in $\mathrm{P}$ concentration when grown under $\mathrm{P}$ limiting conditions led to lower PUE scores for the over expression 

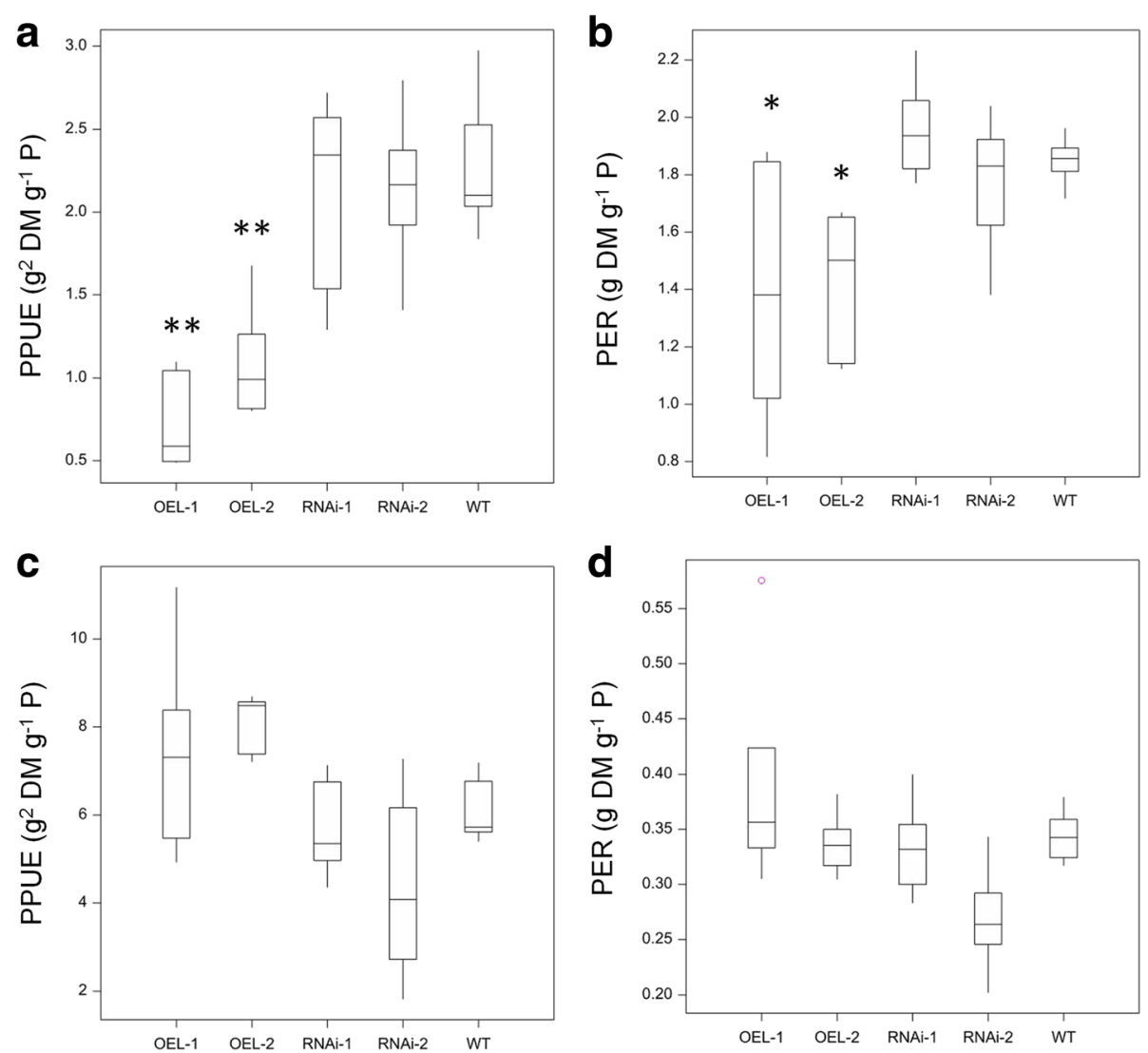

Fig. 8 PPUE and PER of transgenic wheat plants. Plants were grown under both low P (3 $\mu \mathrm{M})$ conditions in sand to seed (a and $\mathbf{b})$ or grown in M2 compost to seed (c and $\mathbf{d}$ ). Double asterisk indicates significant difference $p$ val $<0.01$ to WT Fielder

of TaPSTOL but not for the RNAi lines. As a positive increase in yield did not occur with the over expression of TaPSTOL to compensate for the increased P found in the grain, the PUE score was significantly lowered. This was not the case for the OsPSTOL where both an increase in yield along with an increase in P concentration of the tissues were found [18]. This difference in rice versus wheat might be due to some other part of the signalling cascade needing to be identified and combined with increased PSTOL expression to help drive the yield increases under limiting $\mathrm{P}$ growth conditions.

\section{Conclusions}

We have identified and characterized the PSTOL gene in wheat and demonstrated that it controls a number of agronomic characteristics important to breeders and farmers, including altering root growth under P deficiency conditions and increased $\mathrm{P}$ content in the grain. While some of these phenotypes are conserved with PSTOL genes in other plant species, other phenotypes manifest themselves under slightly different $\mathrm{P}$ conditions. In addition, we show that while PSTOL may not influence yield as it does in rice, TaPSTOL modulates flowering time and seed size in wheat. These results demonstrate PSTOL genes in multiple crop species may be important targets for improving agronomic performance, both under P limiting and non $\mathrm{P}$ limiting conditions.

\section{Additional files}

Additional file 1: Table S1. Primers used in this study. (DOCX $33 \mathrm{~kb}$ )

Additional file 2: Figure S1. Location of gene-specific primers and PCR amplification of TaPSTOL genomic regions on DNA extracted from nullisomic (N) / tetrasomic (T) wheat lines. The PCR amplicons correspond to a promoter region (PCR1, $1458 \mathrm{bp}$ ), a promoter and coding region (PCR2, $553 \mathrm{bp}$ ), and a coding region (PCR3, $870 \mathrm{bp}$ ), to demonstrate that TaPSTOL is only present on chromosome 5A. (DOCX $63 \mathrm{~kb}$ )

Additional file 3: Figure S2. T-DNA structure for the three TaPSTOL constructs used in this study. (DOCX $30 \mathrm{~kb}$ ) (DOCX $80 \mathrm{~kb}$ )

Additional file 4: Figure S3. ClustalW alignment of the rice and wheat PSTOL predicted proteins. Conserved amino acids are coloured in red. (DOCX $162 \mathrm{~kb}$ )

Additional file 5: Table S2. Geographical origin of wheat accessions used in this study. (DOCX $30 \mathrm{~kb}$ ) 


\section{Abbreviations}

dpa: Days post anthesis; DW: Dry weight; EST: Expressed sequence tag; ICPMS: Inductively coupled plasma-mass spectrometry; MAGIC: Multiparent advanced generation inter-cross; N: Nullisomic; OE: Over expression; P: Phosphorus; PER: P efficiency ratio; $P_{i:}$ Inorganic phosphate; PPUE: Physiological $P$ use efficiency; PSTOL: Phosphate starvation tolerance; PUE: Phosphate use efficiency; RNAi: RNA interference; T: Tetrasomic; tNOS: Nopaline synthase terminator

\section{Acknowledgements}

The authors would like to thank Olga Murshudova for additional tissue culture media support, Richard Horsnell for gDNA, lan MacKay for information on the NIAB MAGIC populations, and Andy Greenland for his support and advice.

\section{Funding}

This work was supported by the NIAB Trust. The funders had no role in experimental design, data collection and analysis or preparation of the manuscript.

\section{Availability of data and materials}

Sequence data from this article has been deposited to NCBI, with the accession numbers MH043198 and MH043199. Constructs and plant materials are available under MTA from the corresponding author.

\section{Authors' contributions}

$M M, R M H$ and EW designed the experiments. MM, RMH, NG, MC and SB performed the experiments. The article was written by MM, and edited by EW. All authors read and approved the final manuscript.

\section{Ethics approval and consent to participate}

Not applicable.

\section{Competing interests}

The authors declare they have no competing interests.

\section{Publisher's Note}

Springer Nature remains neutral with regard to jurisdictional claims in published maps and institutional affiliations.

\section{Author details}

'The John Bingham Laboratory, NIAB, Huntingdon Road, Cambridge CB3 OLE, UK. ${ }^{2}$ Plant and Crop Sciences Division, School of Biosciences, University of Nottingham, Sutton Bonington Campus, Loughborough LE12 5RD, UK.

\section{Received: 4 April 2018 Accepted: 24 May 2018}

Published online: 08 June 2018

\section{References}

1. Kirkby EA, Johnston A. The ecophysiology of plant-phosphorus interactions. Netherlands: Springer; 2008.

2. Hinsinger $P$. Bioavailability of soil inorganic $P$ in the rhizosphere as affected by root-induced chemical changes: a review. Plant Soil. 2001;237:173-95.

3. Cakmak I. Plant nutrition research: Priorities to meet human needs for food in sustainable ways. Prog Plant Nutr Plenary Lect XIV Int Plant Nutr Colloq. Dordrecht: Springer Netherlands; 2002. p. 3-24.

4. Vance $C P$, Uhde-Stone C, Allan DL. Phosphorus acquisition and use: critical adaptations by plants for securing a nonrenewable resource. New Phytol. 2003;157:423-47

5. Lynch JP, Brown KM. Topsoil foraging - an architectural adaptation of plants to low phosphorus availability. Plant Soil. 2001;237:225-37.

6. Shen J, Yuan L, Zhang J, Li H, Bai Z, Chen X, Zhang W, Zhang F. Phosphorus dynamics: from soil to plant. Plant Physiol. 2011;156(3):997-1005.

7. Herrera-Estrella L, López-Arredondo D. Phosphorus: the underrated element for feeding the world. Trends Plant Sci. 2016;21:461-3.

8. FAOSTAT [Internet]. [cited 2017 Dec 15]. Available from: http://www.fao.org/ faostat/en/\#home

9. López-Arredondo DL, Leyva-González MA, González-Morales SI, López-Bucio J, Herrera-Estrella L. Phosphate nutrition: improving low-phosphate tolerance in crops. Annu Rev Plant Biol. 2014;65:95-123.
10. Ozturk L, Eker S, Torun B, Cakmak I. Variation in phosphorus efficiency among 73 bread and durum wheat genotypes grown in a phosphorusdeficient calcareous soil. Plant Soil. 2005;269:69-80.

11. Malhi SS, Vera CL, Brandt SA. Seed yield potential of five wheat species/ cultivars without and with phosphorus fertilizer application on a P-deficient soil in northeastern Saskatchewan. Agric Sci. 2015;6(02):224.

12. Zhang Z, Liao H, Lucas WJ. Molecular mechanisms underlying phosphate sensing, signaling, and adaptation in plants. J Integr Plant Biol. 2014;56: 192-220.

13. Ni JJ, Wu P, Senadhira D, Huang N. Mapping QTLs for phosphorus deficiency tolerance in rice ( Oryza sativa L.). TAG Theor Appl Genet. 1998, 97:1361-9.

14. Wissuwa M, Yano M, Ae N. Mapping of QTLs for phosphorus-deficiency tolerance in rice ( Oryza sativa L.). TAG Theor Appl Genet. 1998;97:777-83.

15. Wissuwa M, Wegner J, Ae N, Yano M. Substitution mapping of Pup1 : a major QTL increasing phosphorus uptake of rice from a phosphorusdeficient soil. TAG Theor Appl Genet. 2002;105:890-7.

16. Heuer S, Lu X, Chin JH, Tanaka JP, Kanamori H, Matsumoto T, et al. Comparative sequence analyses of the major quantitative trait locus $p$ hosphorus up take 1 ( Pup1) reveal a complex genetic structure. Plant Biotechnol J. 2009;7:456-71.

17. Pariasca-Tanaka J, Chin JH, Dramé KN, Dalid C, Heuer S, Wissuwa M. A novel allele of the P-starvation tolerance gene OsPSTOL1 from African rice (Oryza glaberrima Steud) and its distribution in the genus Oryza. Theor Appl Genet. 2014;127:1387-98.

18. Gamuyao R, Chin JH, Pariasca-Tanaka J, Pesaresi P, Catausan S, Dalid C, et al The protein kinase Pstol1 from traditional rice confers tolerance of phosphorus deficiency. Nature. 2012:488:535-9.

19. Vigueira CC, Small LL, Olsen KM. Long-term balancing selection at the phosphorus starvation tolerance 1 (PSTOL1) locus in wild, domesticated and weedy rice (Oryza). BMC Plant Biol. 2016;16:101.

20. Wissuwa M. Combining a modelling with a genetic approach in establishing associations between genetic and physiological effects in relation to phosphorus uptake. Plant Soil. 2005:269:57-68.

21. Hufnagel B, de Sousa SM, Assis L, Guimaraes CT, Leiser W, Azevedo GC, et al. Duplicate and conquer: multiple homologs of PHOSPHORUS-STARVATION TOLERANCE1 enhance phosphorus acquisition and Sorghum performance on low-phosphorus soils. Plant Physiol. 2014;166:659-77.

22. Azevedo GC, Cheavegatti-Gianotto A, Negri BF, Hufnagel B, e Silva L da C, Magalhaes J V, et al. Multiple interval QTL mapping and searching for PSTOL1 homologs associated with root morphology, biomass accumulation and phosphorus content in maize seedlings under low-P. BMC Plant Biol 2015:15:172.

23. The European Bioinformatics Institute < EMBL-EBI [Internet]. [cited 2012 Sep 1]. Available from: https://www.ebi.ac.uk/

24. Ensembl Plants [Internet]. [cited 2012 Sep 1]. Available from: http://plants. ensembl.org/index.html

25. BLAST: Basic Local Alignment Search Tool [Internet]. [cited 2012 Sep 1]. Available from: https://blast.ncbi.nlm.nih.gov/Blast.cgi

26. National BioResource Project (NBRP):KOMUGI -Integrated Wheat Science Database. - [Internet]. [cited 2012 Sep 1]. Available from: https://shigen.nig. ac.jp/wheat/komugi/

27. URGI BLAST [Internet]. [cited 2015 May 1]. Available from: https://urgi. versailles.inra.fr/blast/blast.php

28. Softberry Home Page [Internet]. [cited 2012 Sep 1]. Available from: http:// www.softberry.com/

29. InterPro protein sequence analysis \& classification $<$ InterPro $<$ EMBL-EB [Internet]. [cited 2012 Sep 1]. Available from: https://www.ebi.ac.uk/interpro/

30. Rubio V, Linhares F, Solano R, Martín AC, Iglesias J, Leyva A, et al. A conserved MYB transcription factor involved in phosphate starvation signaling both in vascular plants and in unicellular algae. Genes Dev. 2001; 15:2122-33

31. Nakagawa S, Niimura Y, Gojobori T, Tanaka H, Miura K. Diversity of preferred nucleotide sequences around the translation initiation codon in eukaryote genomes. Nucleic Acids Res. 2008;36:861-71.

32. Perochon A, Jianguang J, Kahla A, Arunachalam C, Scofield SR, Bowden S, et al. TaFROG encodes a Pooideae orphan protein that interacts with SnRK1 and enhances resistance to the mycotoxigenic fungus fusarium graminearum. Plant Physiol. 2015;169:01056.2015.

33. McElroy D, Zhang W, Cao J, Wu R. Isolation of an efficient actin promoter for use in rice transformation. Plant Cell. 1990;2:163-71. 
34. Bates R, Craze M, Wallington EJ. Agrobacterium -mediated transformation of oilseed rape (Brassica napus). Curr Protoc Plant Biol. 2017;2:287-298. Hoboken; Wiley. https://doi.org/10.1002/cppb.20060.

35. Ishida Y, Tsunashima M, Hiei Y, Komari T. Wheat (Triticum aestivum L.) transformation using immature embryos. In Agrobacterium Protocols. New York: Springer; 2015. p. 189-198.

36. Risacher T, Craze M, Bowden S, Paul W, Barsby T. Highly efficient agrobacterium-mediated transformation of wheat via in planta inoculation. In Transgenic Wheat, Barley and Oats. Humana Press; 2009. p. 115-124.

37. Livak KJ, Schmittgen TD. Analysis of relative gene expression data using real-time quantitative $P C R$ and the 2- $\Delta \Delta C T$ method. Methods. 2001;25:402-8.

38. Magnavaca R, Gardner CO, Clark RB. Evaluation of inbred maize lines for aluminum tolerance in nutrient solution. Genet Asp Plant Miner Nutr. Dordrecht: Springer Netherlands; 1987. p. 255-65.

39. Van Riet L, Nagaraj V, Van den Ende W, Clerens S, Wiemken A, Van Laere A. Purification, cloning and functional characterization of a fructan 6exohydrolase from wheat (Triticum aestivum L.). J Exp Bot. 2006;57:213-23.

40. Xia N, Zhang G, Liu X-Y, Deng L, Cai G-L, Zhang Y, et al. Characterization of a novel wheat NAC transcription factor gene involved in defense response against stripe rust pathogen infection and abiotic stresses. Mol Biol Rep. 2010;37:3703-12.

41. Fulton TM, Chunwongse J, Tanksley SD. Microprep protocol for extraction of DNA from tomato and other herbaceous plants. Plant Mol Biol Report. 1995; 13:207-9.

42. Stomp AM. Histochemical localization of b-glucuronidase. GUS protocols: using the GUS gene as a reporter of gene expression. 1992. p. 103-113.

43. Thomas CL, Alcock TD, Graham NS, Hayden R, Matterson S, Wilson L, Young SD, Dupuy LX, White PJ, Hammond JP, Danku JMC, Salt DE, Sweeney A, Bancroft I, Broadley MR. BMC Plant Biol. 2016;16:214.

44. Hammond JP, Broadley MR, White PJ, King GJ, Bowen HC, Hayden R, et al. Shoot yield drives phosphorus use efficiency in Brassica oleracea and correlates with root architecture traits. J Exp Bot. 2009;60:1953-68.

45. Altschul SF, Gish W, Miller W, Myers EW, Lipman DJ. Basic local alignment search tool. J Mol Biol. 1990;215:403-10.

46. Sears ER. The aneuploids of common wheat. Univ Missouri, Coll Agric Agric Exp Stn Bull. 1954;572:1-59

47. Mackay IJ, Bansept-Basler P, Barber T, Bentley AR, Cockram J, Gosman N, et al. An eight-parent multiparent advanced generation inter-cross population for winter-sown wheat: creation, properties, and validation. G3. 2014;4:160310

48. White J, Law JR, MacKay I, Chalmers KJ, Smith JSC, Kilian A, et al. The genetic diversity of UK, US and Australian cultivars of Triticum aestivum measured by DArT markers and considered by genome. Theor Appl Genet. 2008:116:439-53

49. Zadoks JC, Chang TT, Konzak CF. A decimal code for the growth stages of cereals. Weed Res. 1974;14:415-21.

50. Bentley AR, Horsnell R, Werner CP, Turner AS, Rose GA, Bedard C, et al. Short, natural, and extended photoperiod response in BC2F4 lines of bread wheat with different Photoperiod-1 (Ppd-1) alleles. J Exp Bot. 2013;64: 1783-93.

51. Simmonds J, Scott P, Brinton J, Mestre TC, Bush M, del Blanco A, et al. A splice acceptor site mutation in TaGW2-A1 increases thousand grain weight in tetraploid and hexaploid wheat through wider and longer grains. Theor Appl Genet. 2016;129:1099-112.

52. Ma M, Zhao H, Li Z, Hu S, Song W, Liu X. TaCYP78A5 regulates seed size in wheat ( Triticum aestivum ). J Exp Bot. 2016;67:1397-410.

53. Akhunov ED, Akhunova AR, Linkiewicz AM, Dubcovsky J, Hummel D, Lazo G, et al. Synteny perturbations between wheat homoeologous chromosomes caused by locus duplications and deletions correlate with recombination rates. Proc Natl Acad Sci U S A. 2003;100:10836-41.

54. Oi LL, Echalier B, Chao S, Lazo GR, Butler GE, Anderson OD, et al. A chromosome bin map of 16,000 expressed sequence tag loci and distribution of genes among the three genomes of polyploid wheat. Genetics. 2004;168:701-12.

\section{Ready to submit your research? Choose BMC and benefit from:}

- fast, convenient online submission

- thorough peer review by experienced researchers in your field

- rapid publication on acceptance

- support for research data, including large and complex data types

- gold Open Access which fosters wider collaboration and increased citations

- maximum visibility for your research: over $100 \mathrm{M}$ website views per year

At BMC, research is always in progress.

Learn more biomedcentral.com/submissions 